\title{
Correlation of Serum Levels of Interleukin-1及 and CCL 24 with Severity of Persistent Allergic Rhinitis in Children
}

\author{
${ }^{1}$ Alshimaa L. Abdallah*, ${ }^{1}$ Hanaa M. El Maghraby, ${ }^{2}$ Mohamed S. El Gandy, \\ ${ }^{3}$ Marwa A. Shabana, ${ }^{1}$ Heba A. Mohammed \\ ${ }^{1}$ Medical Microbiology and Immunology Department, Faculty of Medicine, Zagazig University, Egypt \\ ${ }^{2}$ Otolaryngology Department, Faculty of Medicine, Zagazig University, Egypt \\ ${ }^{3}$ Clinical Pathology Department, Faculty of Medicine - Zagazig University, Egypt
}

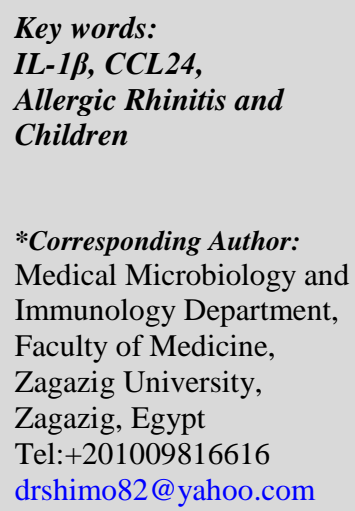

*Corresponding Author: Medical Microbiology and Immunology Department, Faculty of Medicine, Zagazig University, Zagazig, Egypt Tel:+201009816616 drshimo82@yahoo.com

\begin{abstract}
Background: Allergic rhinitis (AR) is a distressing clinical presentation especially in pediatric age which affects quality of life and may predispose to bronchial asthma. Various inflammatory biomarkers might be involved in allergic rhinitis pathogenesis and correlated with its severity such as IL1 $\beta$ and CCL 24. Objectives: This study aims to detect serum level of IL $1 \beta$ and CCL24 in studied pediatric patients and correlate their levels with the severity of allergic rhinitis and with comorbid asthma in children. Methodology: Peripheral blood eosinophil count was detected and serum level of IgE, IL1 $\beta$ and CCL24 were assayed in pediatric patients with allergic rhinitis using ELISA. In addition, correlation of their levels with the severity of AR. Results: Eosinophil count and serum levels of IL1 $\beta$ and CCL24 were significantly elevated in (AR) patients compared with the controls $\left(P=0.00001^{*}\right),\left(P=0.026^{*}\right)$ and $\left(P=0.017^{*}\right)$ respectively. Parental smoking and Associated Asthma of high statistical significance when correlated with severity of allergic rhinitis $(P=0.005)$ and $(P<0.001)$ respectively. Family history of allergy\& allergy in other sibling were also significantly correlated with severity of $A R$ $(P=0.093)$ and $(P=0.02)$ respectively. Conclusion: This study clarifies the evidence that $I L-1 \beta$ is an important inflammatory biomarker for pathogenesis and severity of allergic rhinitis and it might predispose to other allergic diseases subsequently it may be investigated as a therapeutic target especially in severe cases.
\end{abstract}

\section{INTRODUCTION}

Allergic rhinitis (AR) is an immunoglobulin E-mediated type of inflammation of the upper airway, which is induced by allergens and regulated by $\mathrm{T}$ cells. Worldwide, the prevalence of allergic rhinitis has raised; approximately 10 to $30 \%$ of adults and $40 \%$ of children are affected ${ }^{1}$.

AR has a major impact on quality of life by causing symptoms of sneezing, nasal congestion, nasal pruritus, rhinorrhea and obstruction of the nasal passages. Furthermore, it may contribute to secondary complications and co-morbidities (acute and chronic sinusitis, asthma exacerbations, eustachian tube dysfunction and chronic otitis media subsequently speech delay in pediatric populations and in rare cases permanent hearing damage). Moreover, in children, rhinitis can lead to craniofacial abnormalities due to chronic mouth breathing ${ }^{2}$.

The Allergic Rhinitis and its Impact on Asthma (ARIA) 2016 update recommends introducing the terms "intermittent" and "persistent" on classification of allergic rhinitis instead of "seasonal" and "perennial" depending on persistence period of symptoms. The severity of allergic rhinitis differentiated into, mild, moderate/severe based on symptoms and their effect on social life, school and work performance ${ }^{3}$.

The pathophysiology of AR is a multifactorial process including; effector cells enhancement and migration, inflammatory cells release of mediators, chemokines and cytokines, and eventually damage to the nasal epithelium and nerve endings ${ }^{4}$.

Inflammatory biomarkers play fundamental role not only in diagnosis and staging AR but also in monitoring progression, and response to therapy. For instance, IL$1 \beta$ is a proinflammatory cytokine linked to the promotion of inflammation in severe allergic rhinitis, development of chronic obstructive pulmonary disease (COPD), asthma and its exacerbations due to infection ${ }^{5,6,7}$.

Regarding chemokines, C-C Motif Chemokine Ligand 24 (CCL24) (also known as eotaxin-2 or myeloid progenitor inhibitor factor-2), is a chemokine involved in the pathogenesis of asthma and rhinitis. It contributes to the fibrocytes recruitment from blood to the airway in atopy. ${ }^{8,9}$.

Estimation of inflammation biomarkers level offers insight on the mechanisms of allergic rhinitis, monitoring its severity, and may provide target for novel therapy. The previous studies targeting various 
biomarkers for AR have been published over the past decades based on their detection in nasal mucosa. Our study was directed to assess their role in serum.

\section{METHODOLOGY}

\section{Study design:}

This case-control study was conducted at the outpatient clinic of Otolaryngology, Clinical pathology departments, Allergy Unit of Zagazig University Hospitals and Microbiology \& Immunology Departments, Faculty of Medicine, Zagazig University and It was carried out between Mars 2021 and August 2021.

\section{Ethical approvals}

The study protocol was reviewed and approved by the Institutional Review Board (IRB) (no. 6784), Faculty of Medicine, Zagazig University, Egypt. The study complied with the guidelines of the Declaration of Helsinki 1975.The parents of all participants agreed and signed the informed consent.

\section{Subjects:}

A total of 200 participants were enrolled in the study. They included 100 pediatric patients with allergic rhinitis and 100 apparently healthy non-atopic child as controls. The two groups were age and gender matched.

The patients were clinically diagnosed as persistent allergic rhinitis (rhinorrhea, nasal obstruction, nasal itching, and sneezing that persist for more than four days per week or persist for more than 4 weeks). Patients were classified into 3 groups mild, moderate and severe; according to the AR and its impact on asthma (ARIA) depending on presence or absence of impairment in sleep, impairment of normal daily activities (work performance or school activity), troublesome symptoms ${ }^{3}$.Patients were also examined for associated asthma.

\section{Exclusion criteria:}

Exclusion criteria included children $<6$ years old, those on medications as steroids, antihistaminic and unconsented patients.

Methods:

\section{Samples}

Five $\mathrm{ml}$ of blood were obtained from each participant and divided into; $2 \mathrm{ml}$ blood in the EDTA tube for eosinophils counting and $3 \mathrm{ml}$ placed into plain tube for serum collection for ELISA. Serum was obtained by allowing samples to clot for 30 minutes followed by centrifugation for 10 minutes at approximately $3000 \times \mathrm{g}$. and stored at $-20^{\circ} \mathrm{C}$ until used.

\section{Peripheral blood eosinophils counting}

Two $\mathrm{ml}$ whole blood in the EDTA tube was utilized for complete blood counts using an XS500i Hematology analyzer (Sysmex, Kobe, Japan). In addition, peripheral blood differential cell analysis was conducted, using the blood film.

\section{Skin prick test (SPT)}

Skin prick test (SPT) to case group was performed at the Allergy and Immunology Unit, Faculty of Medicine, Zagazig University. Allergen panel used (homemade extracts of pollen, house dust, smoke, wool, cotton, mixed fungi, hay rice dust, clover and maize). POSITIVE SKIN TEST HISTAMINE (port Washington, NY, USA) was used as a positive control and saline as a negative control. The test was interpreted by measuring the size of the wheal after $20 \mathrm{~min}$. The patient was considered sensitized when wheal diameter for the tested allergen was $3 \mathrm{~mm}$ or more and associated with erythema ${ }^{\mathbf{1 0}}$.

Measuring of total IgE by Enzyme linked immunosorbent assay (ELISA)

Quantitative determination of total IgE in serum by ELISA according to manufacturer's instructions (IMMUNOSPEC Corporation, Canoga Park, CA 91303, USA). The optical density of each well was immediately determined using a micro plate reader (Stat Fax® 303 Plus) set to $450 \mathrm{~nm}$.

\section{Measuring of Serum Level of IL $-1 \beta$ and CCL24}

Quantitative determination of Serum Level of IL- $1 \beta$ and CCL24 were done using double-antibody sandwich enzyme-linked immunosorbent assay. Human IL-1 $\beta$ ELISA kit (USA. Catalogue No.201-12-0144) and Human CCL24ELISA kit (USA. Catalogue No. 201-120059) according to the manufacturer's instructions. The optical density of each well was immediately determined using a micro plate reader (Stat Fax ${ }^{\circledR} 303$ Plus) set to $450 \mathrm{~nm}$.

\section{Statistical analysis:}

After data collection, data were coded, entered and analyzed using SPSS (Statistical Package for Social Science) version 25. Qualitative data were presented as frequencies and percentages while, quantitative data were presented as mean, standard deviations (SD). Quantitative data of two independent normally distributed groups were compared using student $t$ test while Qualitative independent data were compared using Chi square test. P value $(\leq 0.05)$ was considered statistically significant difference and $<0.001$ is considered highly significant difference

\section{RESULTS}

A total 200 participants were enrolled in this study. They were (100) pediatric patients with allergic rhinitis with mean age of $8.5 \pm 1.5$, boys/girls: $66 / 34$ and 100 apparently healthy non-atopic child with mean age of $8.8 \pm 2.2$, boys/girls: $63 / 37$

There were statistically significant differences in IgE serum level and eosinophils count among the studied groups $(P<0.001)$ and $(P<0.00001)$ as shown in table 1. Twenty-six (26) AR patients had normal total $\operatorname{IgE}$ $(26 \%)$. 
Table1: The characteristics of the study participants

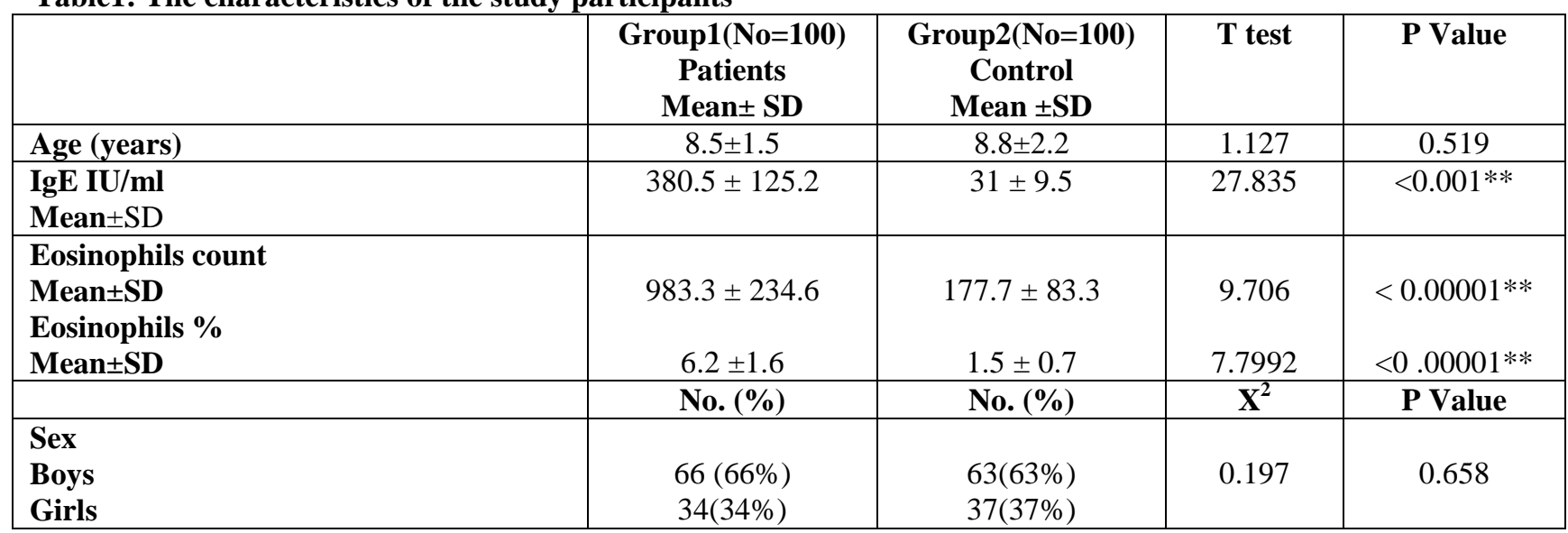

$\mathrm{T}$ test (Student $\mathrm{t}$ test), $\mathrm{X} 2=$ Chi-Square test, ${ }^{* *}=$ Highly significant

Serum level of IL1 $\beta$ and CCL24 were assessed by ELISA in all our studied groups and they were significantly elevated in allergic rhinitis (AR) patients were compared with the controls $\left(P=0.026^{*}\right)$ and $\left(P=0.017^{*}\right)$, respectively as shown in table 2,3 .

Table2: Serum level of IL1 $\beta$ in the studied participants

\begin{tabular}{|l|c|c|c|c|}
\hline $\begin{array}{l}\text { Serum level } \\
(\mathbf{p g} / \mathbf{m l})\end{array}$ & $\begin{array}{c}\text { Group1(No=100) } \\
\text { Patients }\end{array}$ & $\begin{array}{c}\text { Group2(No=100) } \\
\text { Control }\end{array}$ & T test & p value \\
\hline Mean \pm SD & $1825.12 \pm 523.54$ & $1653.13 \pm 452.51$ & 2.486 & $0.026^{*}$ \\
\hline
\end{tabular}

$\mathrm{T}$ test (Student $\mathrm{t}$ test)

Table3: Serum level of CCL24 in the studied participants

\begin{tabular}{|l|c|c|c|c|}
\hline $\begin{array}{l}\text { Serum level } \\
(\mathbf{p g} / \mathbf{m l})\end{array}$ & $\begin{array}{c}\text { Group1(No=100) } \\
\text { Patients }\end{array}$ & $\begin{array}{c}\text { Group2(No=100) } \\
\text { Control }\end{array}$ & T test & p value \\
\hline Mean \pm SD & $318.45 \pm 112.35$ & $279.65 \pm 95.22$ & 2.635 & $0.017^{*}$ \\
\hline
\end{tabular}

T test (Student $\mathrm{t}$ test)

We classified the patients depending on symptoms severity into 2 subgroups: subgroup 1 including children with intermittent allergic rhinitis and mild persistent allergic rhinitis and subgroup 2 including those with moderate to severe persistent allergic rhinitis. There were 64 patients in subgroup 1 and 36 patients in subgroup 2. By comparing the different assayed markers among the two subgroups, there was high statistically significant difference among them as regard serum level of IL1 $\beta$ and IgE $(P<0.001)$ while serum level of CCL24 was not significantly different $(\mathrm{P}=0.491)$ as shown in table4

Table 4: Comparison of IL1 $\beta$, CCL24 and total IgE level according to severity of allergic rhinitis

\begin{tabular}{|l|c|c|c|c|}
\hline Laboratory Tests & $\begin{array}{c}\text { Subgroup1 (No.=64) } \\
\text { Mean } \pm \text { SD }\end{array}$ & $\begin{array}{c}\text { Subgroup2 (No.=36) } \\
\text { Mean } \pm \text { SD }\end{array}$ & T test & p value \\
\hline IgE $(\mathbf{I U} / \mathbf{m l})$ & $276.52 \pm 37.01$ & $354.25 \pm 90.72$ & 4.916 & $<0.001^{* *}$ \\
IL1 $\beta(\mathbf{p g} / \mathbf{m l})$ & $2375.3 \pm 182.4$ & $2641.3 \pm 351.5$ & 4.2314 & $<0.001^{* *}$ \\
CCL24(pg/ml) & $397.2 \pm 115.3$ & $456.1 \pm 291.8$ & 1.161 & 0.491 \\
\hline
\end{tabular}

When the correlation of different factors with the severity of allergic rhinitis in both groups were evaluated, we found that parental smoking and associated asthma showed high statistically significant correlation $(P=0.005)$ and $(P<0.001)$ respectively, in addition, family history of allergy\& allergy in other sibling were also significant $(P=0.093)$ and $(P=0.02)$ respectively. Meanwhile when we analyzed associated urticaria; it was statistically insignificant $(P=0.630)$ as shown in table 5 
Table 5: Correlation of different factors with severity of allergic rhinitis

\begin{tabular}{|l|c|c|c|c|c|}
\hline & $\begin{array}{c}\text { Subgroup1 } \\
\text { (No.=64) No. (\%) }\end{array}$ & $\begin{array}{c}\text { Subgroup2 } \\
\text { (No.=36) No. (\%) }\end{array}$ & $\begin{array}{c}\text { Odds } \\
\text { ratio(95\% CI) }\end{array}$ & $\mathbf{X}^{2}$ & P value \\
\hline Family history of allergy & $55(85 \%)$ & $26(72.2 \%)$ & $2.35(0.85-6.48)$ & 2.816 & 0.093 \\
\hline Parental smoking & $19(29.7 \%)$ & $21(58.3 \%)$ & $0.3(0.13-0.71)$ & 7.878 & $0.005^{* *}$ \\
\hline Allergy in other sibling & $25(39 \%)$ & $6(16.7 \%)$ & $3.2(1.17-8.8)$ & 5.402 & $0.02^{*}$ \\
\hline $\begin{array}{l}\text { History of associated } \\
\text { urticaria }\end{array}$ & $15(23 \%)$ & $10(27.8 \%)$ & $0.79(0.31-2.02)$ & 0.231 & 0.630 \\
\hline $\begin{array}{l}\text { History of associated } \\
\text { asthma }\end{array}$ & $4(6 \%)$ & $17(47 \%)$ & $0.075(0.022-0.25)$ & 23.313 & $<0.001^{* *}$ \\
\hline
\end{tabular}

\section{DISCUSSION}

Allergic rhinitis (AR) is a major atopic inflammatory condition worldwide. AR is the result of environmental exposure of a genetically predisposed persons to allergen. Allergic rhinitis is diagnosed by medical history, clinical examination and detection of allergenspecific IgE (skin prick tests or serum-specific IgE) ${ }^{11}$

In our study, the case group (AR patients) had significantly higher mean level of serum IgE as compared to the control group. Similar results were revealed in the study conducted by Sachdeva and his colleagues ${ }^{12}$. Moreover, another study performed by Abdelmaksoud and his coworkers ${ }^{13}$ but in different age groups had similar results

Normal total IgE was detected in $26 \%$ of cases and elevated in $74 \%$ of them in current study. Concerning measuring total IgE, Ganesan and coworkers ${ }^{\mathbf{1 4}}$ in their study reported only $45.3 \%$ of children had elevated serum total IgE levels, while Refaat and his colleagues ${ }^{15}$ found that $80 \%$ of allergic rhinitis patients had elevated total IgE. The threshold for diagnosing allergic disease and the ability to discriminate between allergic conditions by total IgE assessment are lacking $\mathbf{1 6}$. Different countries adopt different reference values of total IgE for allergy diagnosis ${ }^{*}$ Moreover, normal total IgE cannot exclude significant allergy specially in pediatric group and other IgE-independent pathways might be responsible for mediating allergy in those patients ${ }^{17,18,19}$.

The correlation between eosinophils counts and allergic disease has been known for many years and they were previously investigated in nasal smear and in peripheral blood in patients of allergic rhinitis ${ }^{20}$. Concerning eosinophils count peripheral blood, it was significantly elevated in group 1 than group 2 $(P<0.00001)$. This was in accordance with Gupta and his colleagues ${ }^{21}$ in their case control study which evaluated olfaction in allergic rhinitis patients. Yoon and his colleagues ${ }^{22}$ also in their study on $\mathrm{AR}$ in preschool children had found similar result as eosinophils count was significantly increased in AR patient compared to healthy ones' On the other hand, Mikolajczyk and his colleagues ${ }^{20}$ reported that $94.29 \%$ of their AR patients had no eosinophilia and majority of patients in another study had shown blood absolute eosinophil count levels of $<500$ cell per cu.mm regardless of the severity of clinical disease ${ }^{23}$. Jagdeeshwar and his colleagues ${ }^{24}$ explained and concluded that a normal blood absolute eosinophil count levels were detected in AR with nasal symptoms only, whereas they were increased in AR patients with nasal and respiratory symptoms

The previous studies of allergic rhinitis highlighted the role of inflammatory biomarkers assessment in diagnosis conformation, especially in children. A study done by Sim and his colleagues ${ }^{25}$ reported that IL-1 $\beta$ produced by nasal epithelial cells were increased in nasal lavage fluids from patients with allergic rhinitis especially after allergen challenge and this supported the results of our study concerning serum total IL $1 \beta$ which was significantly higher in patients with allergic rhinitis than control group. This is concordant with the results obtained by Han and his coworkers ${ }^{7}$.

Allergic rhinitis is linked to a systemic inflammatory response leading to upregulation of proinflammatory mediators' expression. This associates allergic rhinitis to comorbid conditions such as asthma, chronic hyperplastic eosinophilic sinusitis, nasal polyps, and exudative otitis media. This systemic inflammatory condition was proved by the finding that local nasal corticosteroids efficiently decrease the local inflammation in the nares, but it failed to control inflammation in tissues involved in the comorbid conditions ${ }^{26}$.

Serum level of CCL24 was elevated in allergic rhinitis (AR) patients in comparison with the controls $\left(P=0.017^{*}\right)$ and this result was the same adopted by lee $2002{ }^{27}$ who reported that CCL24 was significantly higher in the allergic rhinitis group than in the nonallergic rhinitis and normal control group $(\mathrm{p}<0.01$, $\mathrm{p}<0.01)$.In addition, De Corso and his colleagues ${ }^{7}$ showed that high statistical difference in the levels of eotaxin-2 (CCL24) in nasal secretions in patients with persistent allergic rhinitis (PAR) in comparison to healthy participants $(128.9 \pm 51.7 \quad \mathrm{pg} / \mathrm{mL}$ in comparison to $16.4 \pm 10.7 \mathrm{pg} / \mathrm{mL}$ ) 
The main sources of CCL24 in the human body are fibroblasts, cutaneous epithelial, nasal epithelial cells, and macrophages. Both serum or plasma concentration and tissue expression of eotaxins is high in allergic and inflammatory processes, it can be suspected that the activation of cells secreting these chemokines occurs not only in tissues, but also in the blood stream ${ }^{28}$.

The case group was classified into 2 subgroups based on the duration of symptoms and severity of the condition subgroup 1 were children with intermittent and mild persistent allergic rhinitis versus subgroup 2 including those with moderate to severe persistent allergic rhinitis. Different assayed markers were compared between the two subgroups, and there was high statistically significant difference among them as regard Serum level of IL1 $\beta$ and $\operatorname{IgE}(P<0.001)$ while serum level of CCL24 was not significantly different $(\mathrm{P}=0.491)$ and this was agreed to some extent with Han and his coworkers ${ }^{7}$ in significant difference of IL1 $\beta$ among two groups $(p=0.003)$. On contrary, CCL-24 (an eosinophils activation marker), were significantly increased in Group $2(\mathrm{p}=0.039)$ and total $\mathrm{IgE}$ level was not significant different between two groups $(\mathrm{p}=$ 0.258). This difference can be explained that patients in subgroup 2 in our study were stable regarding lower airway hypersensitivity, while in Han and coworker study the patients had active asthma. Different studies showed that eotaxins are linked to poor asthma control $^{29}$.

Association of nasal symptoms with the total $\operatorname{IgE}$ was not statistically significant by study performed by Ganesan and his colleagues ${ }^{13}$ while Azid et al., ${ }^{17}$ who perform their study on Malaysian population to detect relevance of total $\operatorname{IgE}$ and allergic diseases and they concluded correlation of elevated total IgE levels with disease severity . Also, Karli et al., ${ }^{30}$ who concluded that the determination of $\operatorname{IgE}$ in allergic rhinitis is a supportive method. However, it cannot be recommended for routine use because of the time loss and high cost.

At the end of our study, we tried to trace the correlation of different factors to severity of allergic rhinitis in two subgroups, we found that paternal smoking and patient associated asthma had high statistical difference $(P=0.005)$ and $(P<0.001)$ respectively. In addition, family history of allergy \& allergy in other sibling were also significant $(P=0.093)$ and $(P=0.02)$ respectively. This was agreed with Han $e t$ al., ${ }^{7}$ who evaluated the correlation of different factors including perinatal conditions, environmental aspects, socioeconomic factors and family history of allergic disease with the severity of AR and found that perinatal, environmental, and socioeconomic factors had no correlation with moderate and severe AR. They reported that parental history of allergic rhinitis and increased expression of IL-1 $\beta$ is a significant risk factors of moderate to severe $\mathrm{AR}(\mathrm{p}=0.011$ and $\mathrm{p}=0.030)$ respectively.

\section{CONCLUSION}

This study clarifies the evidence that high level of IL-1 $\beta$ may promote inflammation in severe allergic rhinitis and could be used as a marker of severity, subsequently it may be investigated as a therapeutic target.

\section{Recommendations:}

We recommend further studies on different age groups with larger sample size to ensure role of CCL24 and investigate role of IL1 $\beta$ as a therapeutic target.

This manuscript has not been previously published and is not under consideration in the same or substantially similar form in any other reviewed media. I have contributed sufficiently to the project to be included as author. To the best of my knowledge, no conflict of interest, financial or others exist. All authors have participated in the concept and design, analysis, and interpretation of data, drafting and revising of the manuscript, and that they have approved the manuscript as submitted.

\section{REFERENCES}

1. World Allergy organization (WAO). In-Depth Review of Allergic Rhinitis. Available at: https://www.worldallergy.org/education-andprograms/education/allergic-disease-resource center/professionals/in-depth-review-of-allergicrhinitis. Updated Oct 2020. Accessed Mar 11, 2021.

2. Shen Y, Ke X, Yun L, Hu GH, Kang HY, Hong SL. Decreased expression of interleukin-37 and its anti-inflammatory effect in allergic rhinitis. Mol. Med. Rep. (2018). 17, 1333-1339.

3. Brozek JL, Bousquet J, Agache I, Agarwal A, Bachert C, Bosnic-Anticevich S, BrignardelloPetersen R, Canonica GW, Casale T, Chavannes $\mathrm{NH}$, et al. Allergic rhinitis and its impact on asthma (ARIA) guidelines-2016 revision. J Allergy Clin Immunol. 2017; 140:950-8.

4. Watts Annabelle M., Cripps Allan W., West Nicholas P., Cox Amanda J.Modulation of Allergic Inflammation in the Nasal Mucosa of Allergic Rhinitis Sufferers With Topical Pharmaceutical Agents . Frontiers in Pharmacology. 2019; 10, 294 https://doi.org/10.3389/fphar.2019.00294.

5. Knipping K, Knippels LM, Dupont C, Garssen J. Serum biomarkers for allergy in children. Pediatr Allergy Immunol.; (2017). 28:114-23.

6. Howrylak JA, Nakahira K. (2017). Inflammasomes: key mediators of lung immunity. Annu Rev Physiol.; 79:471-94

7. Han MW, Kim SH, Oh I, Kim YH, Lee J. Serum 
IL-1 $\beta$ can be a biomarker in children with severe persistent allergic rhinitis. Allergy, Asthma \& Clinical Immunology.; (2019). 15(1):1-9.

8. De Corso E, Baroni S, Battista M, Romanello M, Penitente R, Di Nardo W, Passali GC, Sergi B, Fetoni AR, Bussu F, et al. Nasal fluid release of eotaxin-3 and eotaxin-2 in persistent sinonasal eosinophilic inflammation. Int Forum Allergy Rhinol.; (2014) 4:617-24.

9. Perić, A., Mirković, C. Š., Đurđević, B. V., Perić, A. V., \& Vojvodić, D. Eosinophil Chemokines and Clara Cell Protein 16 Production in Nasal Mucosa of Patients with Persistent Allergic Rhinitis. The Eurasian journal of medicine, (2017). 49(3), 178182. https://doi.org/10.5152/eurasianjmed.17203

10. ASCIA. Skin prick testing for the diagnosis of allergic disease: A manual for practitioners. Australasian society of clinical immunology and allergy Inc. 2016

11. Platt MP, Wulu JA. Rational Approach to Allergy Testing. Otolaryngologic Clinics of North America. 2017 Dec 1;50(6):1103-10.

12. Sachdeva PB, Joshi S, Anand S. Serum vitamin D and immunoglobulin E levels in children of allergic rhinitis: a case-control study from Central India. Int J Contemp Pediatr 2021; 8:1038-42.

13. Abdelmaksoud AA, Bazeed SE, Alemam MF, Aref Z. Relation between serum levels of Vitamin D and Immunoglobulin E in Allergic Rhinitis in Upper Egypt. SVU-International Journal of Medical Sciences. 2021 Jul 30;4(2):69-75.

14. Ganesan S, Al-Saey H, Al-Bouainain M, Larem A, Magdi $\mathrm{MH}$, et al. Prevalence of Inhalant Allergic Rhinitis in Children with Adenoid Hypertrophy: A Prospective Radioallergosorbent Test (Rast) Study. J Otolaryngology ENT Res (2016) 4(5): 00111.

15. Refaat MM, Elnour NA, Shaheen RY, El-Gaaly SA. Study for assessing prevalence and phenotypes of local allergic rhinitis. The Egyptian Journal of Hospital Medicine. 2015 Jul 1;60(1):258-70

16. EL-Aidy AM, Abd Elbary ME, EL-Shennawy G , Morad EA. Correlation between serum IL-23 and serum total IgE levels in allergic rhinitis patients. Egyptian Journal of Medical Microbiology. 2021 Jul 11;30(3):59-63.

17. Azid NA, Sani MM, Zamry AA, Ashari NS, Tan TH, Wong KK, Mohamud R. Total IgE levels and their relevance in the diagnosis of allergy among Malaysian population in the North-East Region of Peninsular Malaysia. Journal of Biomedical and Clinical Sciences (JBCS). 2019 Dec 18;4(2):1-7.

18. Sheldon J, Miller L. Allergy Diagnosis Reference Guide. Clin Biochem. 2014:1-0.

19. Burton OT, Oettgen HC. Beyond immediate hypersensitivity: evolving roles for IgE antibodies in immune homeostasis and allergic diseases. Immunological reviews. $2011 \mathrm{Jul}$;242(1):128-43.

20. Mikolajczyk M, Janukowicz K, Majewska E, Baj Z. Impact of Allergic Rhinitis on Nasal Mucociliary Clearance Time in Children. Int Arch Allergy Immunol. 2019;179(4):297-303. doi: 10.1159/000499740. Epub 2019 May 15. PMID: 31091525.

21. Gupta N, Harit A, Taneja HC, Kumar R, Tripathi AK. Olfaction and Its Correlates in Allergic Rhinitis: A Case Control Study. Indian J Otolaryngol Head Neck Surg. 2019;71(Suppl 3):1782-1786. doi:10.1007/s12070-017-1149-7

22. Yoon J, Choi YJ, Lee E, Cho HJ, Yang SI, Kim YH, Jung YH, Seo JH, Kwon JW, Kim HB, Lee SY, Kim BS, Shim JY, Kim EJ, Lee JS, Hong SJ. Allergic Rhinitis in Preschool Children and the Clinical Utility of FeNO. Allergy Asthma Immunol Res. $2017 \quad$ Jul;9(4):314321. https://doi.org/10.4168/aair.2017.9.4.314

23. Prabakaran J, Dhanapal E, Prasanna V, Jayagar S, Correlation between blood eosinophil count and nasal smear eosinophils with severity of clinical score in allergic rhinitis patients- A cross sectional study JMSCR, 2018; 6 (7): 1134-1137.

24. Jagdeeshwar K, Venumadhav V, Chowdary S, Sudharani V, Kumar V. A study on serum IgE levels, peripheral eosinophils and individual symptoms in patients with non-infective rhinitis and asthma and related conditions. Int J Pharm Pharm Sci 2012; 4:88-92

25. Sim TC, Grant JA, Hilsmeier KA, Fukuda Y, Alam R. Proinflammatory cytokines in nasal secretions of allergic subjects after antigen challenge. Am J Respir Crit Care Med 1994; 149:339-44

26. Borish L. Allergic rhinitis: systemic inflammation and implications for management. Journal of allergy and clinical immunology. 2003 Dec $1 ; 112(6): 1021-31$.

27. Lee KC. Serum Eotaxin and Interleukin-13 Level in Patients with Allergic Rhinitis. Journal of Rhinology. 2002 Nov 1;9(1, 2):24-9.

28. Zajkowska M, Mroczko B. From Allergy to Cancer-Clinical Usefulness of Eotaxins. Cancers. 2021 Jan;13(1):128.

29. Larose MC, Archambault AS, Provost V, Laviolette M, Flamand N. Regulation of eosinophil and group 2 innate lymphoid cell trafficking in asthma. Frontiers in medicine. 2017 Aug 11; 4:136.

30. Karli R, Balbaloglu E, Uzun L, Cinar F, Ugur MB. Correlation of symptoms with total IgE and specific IgE levels in patients presenting with allergic rhinitis. Ther Adv Respir Dis. 2013 Apr;7(2):75-9. doi: 10.1177/1753465812468500. Epub 2012 Nov 29. PMID: 23197073 